\title{
Penerapan Sistem Monitoring Jaringan Dengan Protokol SNMP Pada Router Mikrotik dan Aplikasi Dude Studi Kasus Stikom CKI
}

\author{
ZAENI MIFTAH \\ Program Studi Teknik Informatika \\ STIKOM Cipta Karya Informatika \\ Jl. Raden Inten II No.8, RT.5/RW.14, Duren Sawit, Kota Jakarta Timur 13440 \\ e-mail: zaenimiftah02@gmail.com
}

\begin{abstract}
The internet is a primary need in the educational environment, especially in STIKOM Cipta Karya Informatika. The increasing need for internet users and the increasingly complex needs of installed network devices resulting in increased risk of damage and disruption to internet networks and an impact on decreasing academic activities in universities. Network administrators monitor the network manually which causes a lack of maximum stability in the internet network. To keep the internet network safe and stable and according to the needs of one of the efforts that can be done in maintaining the internet network, it is necessary to do real-time monitoring of network connections so that the network can meet the needs of the campus environment. By using the SNMP Protocol on the Microtic Router and the Dude Application that was built, it can help the network administrator at network monitoring in the college environment in real time. Mikrotik serves as a router that connects with various network devices such as switches, routers, and servers. The results of this study that all devices connected to the network will be detected with the "The Dude" application. If there is a network device that is disconnected because the device is damaged, dead, or the cable is disconnected, there will be notifications on the Dude application, that is, the shifting of the device color from green to red.
\end{abstract}

Keywords: network monitoring, SNMP, The Dude

\begin{abstract}
Abstrak. Jaringan internet merupakan kebutuhan primer di lingkungan pendidikan khususnya di STIKOM Cipta Karya Informatika. Meningkatnya kebutuhan pengguna internet serta semakin kompleks kebutuhan perangkat jaringan yang terpasang mengakibatkan meningkatnya resiko kerusakan serta gangguan pada jaringan internet, dan berdampak pada menurunnya kegiatan akademik pada lingkungan perguruan tinggi. Selama ini seorang administrator jaringan melakukan monitoring jaringan secara manual, sehingga menyebabkan kurang maksimalnya pengelolaan stabilitas jaringan internet. Untuk menjaga agar jaringan internet aman, stabil, dan sesuai kebutuhan, salah satu upaya yang dapat dilakukan dalam menjaga jaringan internet maka perlu dilakukan pemantauan secara real-time terhadap koneksi jaringan sehingga jaringan tersebut dapat memenuhi kebutuhan dilingkungan kampus. Dengan menggunakan Protokol SNMP pada Router Mikrotik dan Aplikasi The Dude yang dibangun, dapat membantu administrator jaringan dalam monitoring jaringan di lingkungan perguruan tinggi secara realtime. Mikrotik sebagai router yang menghubungkan dengan berbagai perangkat jaringan seperti switch, router, dan server. Hasil dari penelitian ini menyatakan bahwa semua perangkat yang terhubung pada jaringan akan terdeteksi dengan aplikasi The Dude. Apabila ada perangkat jaringan yang terputus dikarenakan perangkat rusak, mati, atau kabel terputus maka akan ada informasi pada aplikasi The Dude yaitu berubahnya warna perangkat dari hijau menjadi merah.
\end{abstract}

Kata Kunci: monitoring jaringan, SNMP, The Dude

\section{PENDAHULUAN}

Sekolah Tinggi Ilmu computer Cipta Karya Informatika merupakan Sekolah tinggi yang berlokasi di wilayah Jakarta Timur dan memiliki sistem informasi online yang sudah terintegrasi seperti sistem akademik, sistem perpustakaan online, repositori online, sistem jurnal online, 
absensi online serta alumni-site. Selama ini untuk melakukan monitor jaringan dilingkungan STIKOM Cipta Karya Informatika dilakukan secara manual yaitu menggunakan tes ping hal ini menyebabkan kurang maksimalnya dalam menjaga stabilitas jaringan internet dan sering terjadi keterlambatan dalam penanganan masalah terhadap jaringan internet. tujuan penelitian ini untuk memberikan perbaikan terhadap sistem jaringan yang manual menjadi realtime sehingga seorang administrator dapat cepat menangani jika didapatkan suatu permasalahan terhadap jaringan.

\section{Monitor Jaringan}

Monitoring jaringan komputer merupakan proses pengumpulan dan melakukan analisis terhadap data-data yang melewati pada sebuah jaringan sehingga dapat diketahui keadaan konektivitas antar perangkat pada sebuah jaringan dengan tujuan memaksimalkan seluruh sumber daya yang dimiliki pada jaringan komputer (Pratama et al., 2017).

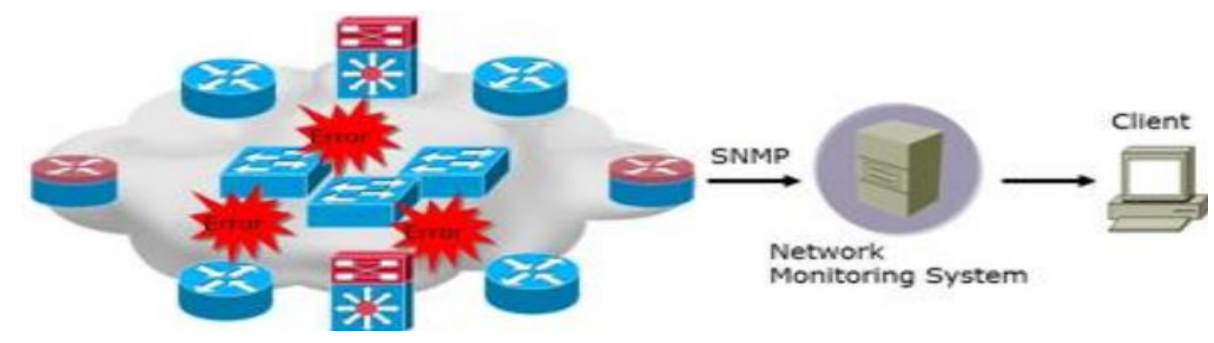

Gambar 1. Network Monitoring System

\section{SNMP (Simple Network Management Protocol)}

SNMP (Simple Network Management Protocol) merupakan sebuah protokol yang bekerja pada Internet Protocol Suite yaitu pada layer 7 dari lapisan OSI. SNMP digunakan untuk memonitor tiap-tiap perangkat yang saling terhubung. Perangkat tersebut diantaranya Router, Switch, Server, Access Point dan perangkat jaringan lainnya. Protokol SNMP digunakan untuk berkomunikasi antara SNMP manager dan SNMP agent, dimana komunikasi pada protokol SNMP yaitu dengan mengirim pesan dalam bentuk User Datagram Protokol (UDP). Sedangkan Internet Protocol digunakan untuk routing tiap pesan antara SNMP manager dan SNMP agent. Pesan yang dikirim disimpan didalam Management Information Base (MIB).

\section{MIB (Managemen Information Base)}

MIB berisi deskripsi hierarki objek yang berisi semua nama objek (OID) yang disusun dalam bentuk struktur tree, dimana daun pohon adalah parameter yang harus diakses oleh Monitor SNMP. Informasi yang ada pada MIB adalah tentang perangkat yang terhubung pada sebuah jaringan seperti versi perangkat lunak jaringan yang berjalan di komputer itu dan ruang hard drive yang tersedia. Perangkat tersebut diidenttifikasi dengan nama Objek identifier (OID) (Sivakumar S.R., 2012). 

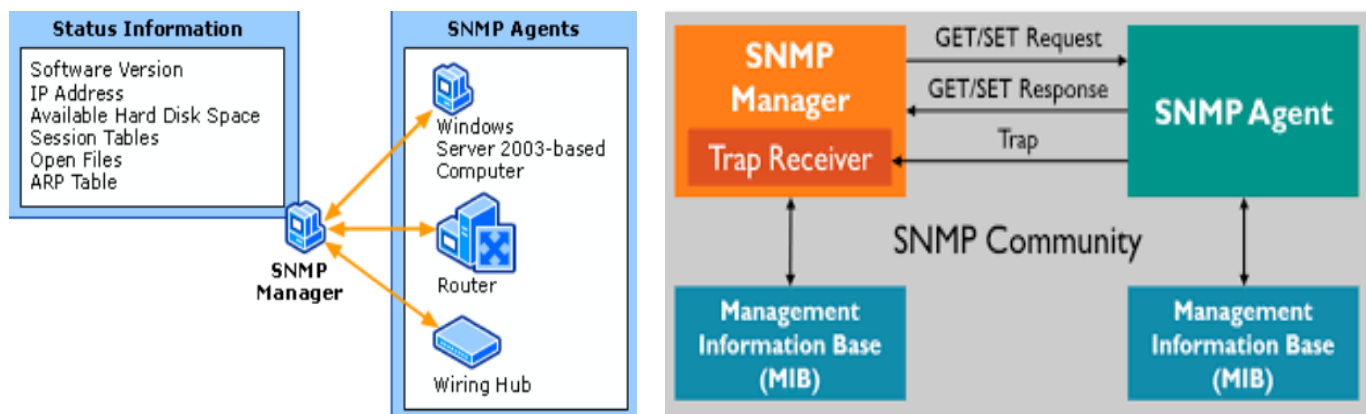

Gambar 2. SNMP Manager dan SNMP Agent

SNMP di desain oleh Internet Engineering Task Force (IETF) untuk pemakaian di internet. SNMP memanfaatkan datagram UDP untuk pesannya pada perangkat jaringan. Karena pesan UDP bersifat unreliable (tidak dapat diandalkan) maka SNMP menggunakan prosedur time out dan retry count untuk memecahkan masalah ini.(Lizarti \& Agustin, 2019)

SNMP melakukan monitoring berdasarkan data yang dikumpulkan dengan parameter yang terkait pada sebuah jaringan. Parameter ini disimpan pada Management Information Base (MIB). Protokol SNMP menggunakan 5 pesan yang dikirim dari SNMP Manager ke SNMP Agent. Pesan tersebut yaitu (GET, GET-NEXT, RESPONSE, SET, and TRAP) (Hui-Ping, ShiDe, \& Xiang-Yin, 2015).

Tabel 1. Proses Kerja SNMP

\begin{tabular}{ll}
\hline \multicolumn{1}{c}{ Perintah } & \multicolumn{1}{c}{ Fungsi } \\
\hline GET & $\begin{array}{l}\text { SNMP Manager mengirimkan permintaan get SNMP ke node yang ditentukan di } \\
\text { pohon MIB untuk mendapatkan satu atau lebih variabel dari agen SNMP }\end{array}$ \\
GET-NEXT & $\begin{array}{l}\text { SNMP Manager mengirimkan permintaan berikutnya SNMP ke node yang } \\
\text { ditentukan berikutnya di pohon MIB dari agen SNMP. }\end{array}$ \\
GET-RESPONSE & $\begin{array}{l}\text { SNMP Agent merespons dengan pesan GET-RESPONSE dengan informasi yang } \\
\text { diminta atau indikasi kesalahan mengapa permintaan tidak dapat diproses }\end{array}$ \\
SET & $\begin{array}{l}\text { SNMP Manager menggunakan perintah SNMP SET untuk mengatur atau } \\
\text { mengubah nilai satu atau lebih variabel dalam agen SNMP } \\
\text { SNMP Agent mengirim pesan TRAP untuk melaporkan manajer SNMP tentang } \\
\text { proses tersebut. }\end{array}$ \\
\hline
\end{tabular}

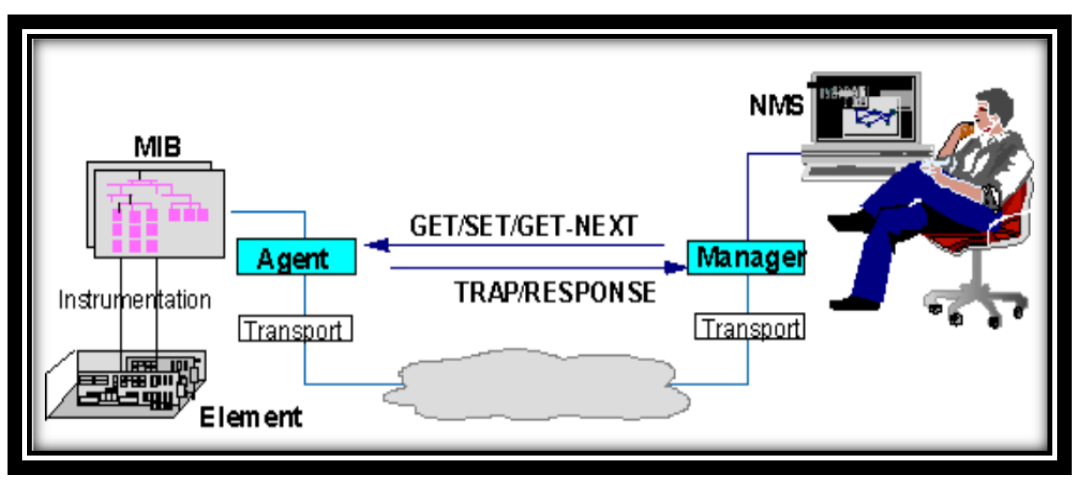

Gambar 3. Proses Kerja Protokol SNMP

\section{The Dude}

The Dude adalah program NMS (Network Monitoring and Management System) yang disediakan oleh Mikrotik secara gratis. The Dude didesain untuk menampilkan semua perangkat yang terhubung jaringan dalam bentuk map atau topologi, sehingga dapat mewakilkan struktur 
sebuah jaringan computer, serta memungkinkan user untuk membuat skema jaringan yang ada baik secara manual atau menggunakan automatic network discovery tool (Adi, 2015).

Aplikasi The Dude pada sistem Mikrotrik dapat membantu kinerja seorang administrator jaringan dalam mendeteksi permasalahan yang terjadi pada jaringan computer (Setiawan \& Sabiq, 2018).

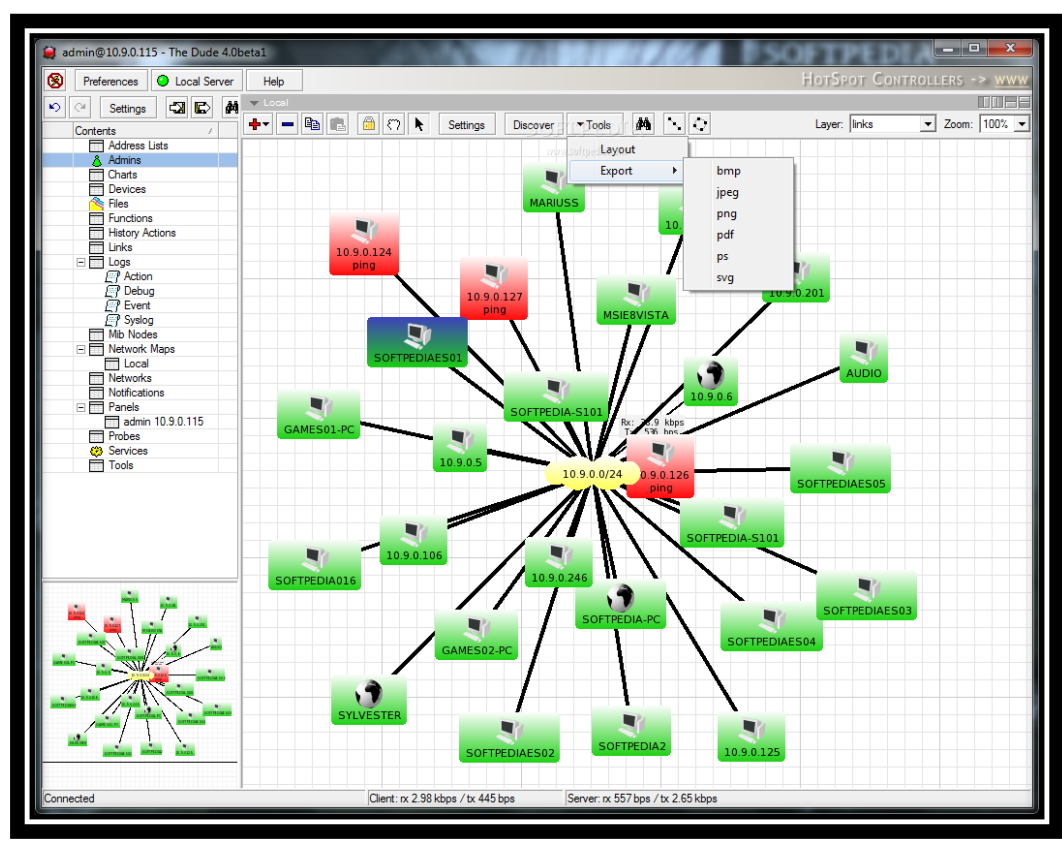

Gambar 4. Aplikasi The Dude

\section{METODE}

Metode yang digunakan untuk melakukan Penerapan Sistem Monitoring Jaringan dengan Protokol SNMP pada Router Mikrotik dan Aplikasi The Dude di STIKOM Cipta Karya Informatika ini dilakukan menggunakan observasi dan pengumpulan materi pembelajaran mengenai prinsip kerja protokol SNMP dan kemudian dilakukan desain sesuai topologi jaringan yang digunakan. Selanjutnya dilakukan penerapan sistem monitoring jaringan sesuai rancangan dan terakhir pengujian terhadap semua komputer yang terhubung dan yang tidak terhubung pada jaringan

Perancangan Sistem Monitoring Jaringan ini menggunakan perangkat yakni 2 unit Router Mikrotik Tipe RB450G, 7 unit Switch, 2 unit Server, beberapa PC (Personal Computer), dan Laptop yang terhubung jaringan di STIKOM Cipta Karya Informatika. Flowchart penelitian ditunjukkan oleh gambar berikut: 


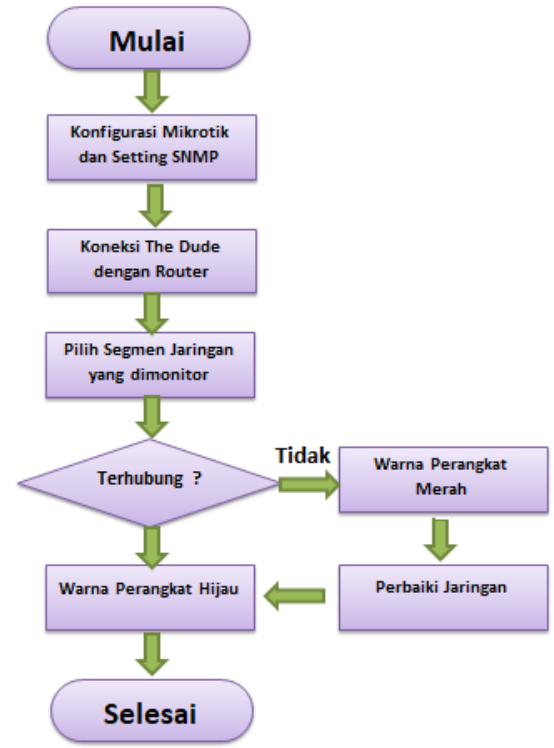

Gambar 5. Flowchart Penelitian

\section{HASIL DAN PEMBAHASAN}

Sistem Monitoring Jaringan yang dalam penelitian ini diimplementasikan pada jaringan komputer yang telah dibangun di STIKOM Cipta Karya Informatika. Bentuk topologi jaringan kampus yang telah dibangun menggunakan topologi star.

\section{Hardware dan Software yang Digunakan}

Hardware

- Server (Processor core i3, RAM 4GB, HDD 150 GB)

- Router Mikrotik Level 6

- Switch

- PC dan Laptop

Software

- Sistem Operasi Windows 7

- Aplikasi The Dude

Tabel IP Address pada jaringan ditunjukkan pada table 2.

Tabel 2. IP Address

\begin{tabular}{lll}
\hline Perangkat/Device & IP Address & Subnetmask \\
Router & 192.168 .10 .2 & 255.255 .255 .0 \\
& 20.20 .20 .1 & 255.255 .255 .0 \\
Server 1 & 20.20 .20 .27 & 255.255 .255 .0 \\
Server 2 & 20.20 .20 .28 & 255.255 .255 .0 \\
PC/Laptop & 20.20 .20 .21 & 255.255 .255 .0 \\
& $20.20 .20 . \mathbf{2 2}$ & 255.255 .255 .0 \\
& 20.20 .20 .23 & 255.255 .255 .0 \\
& $20.20 .20 . \mathbf{2 4}$ & 255.255 .255 .0 \\
& 20.20 .20 .25 & 255.255 .255 .0 \\
& 20.20 .20 .4 & 255.255 .255 .0 \\
& 20.20 .20 .7 & 255.255 .255 .0 \\
& 20.20 .20 .10 & 255.255 .255 .0 \\
\hline
\end{tabular}


desain network menggunakan GNS3 seperti pada gambar berikut :

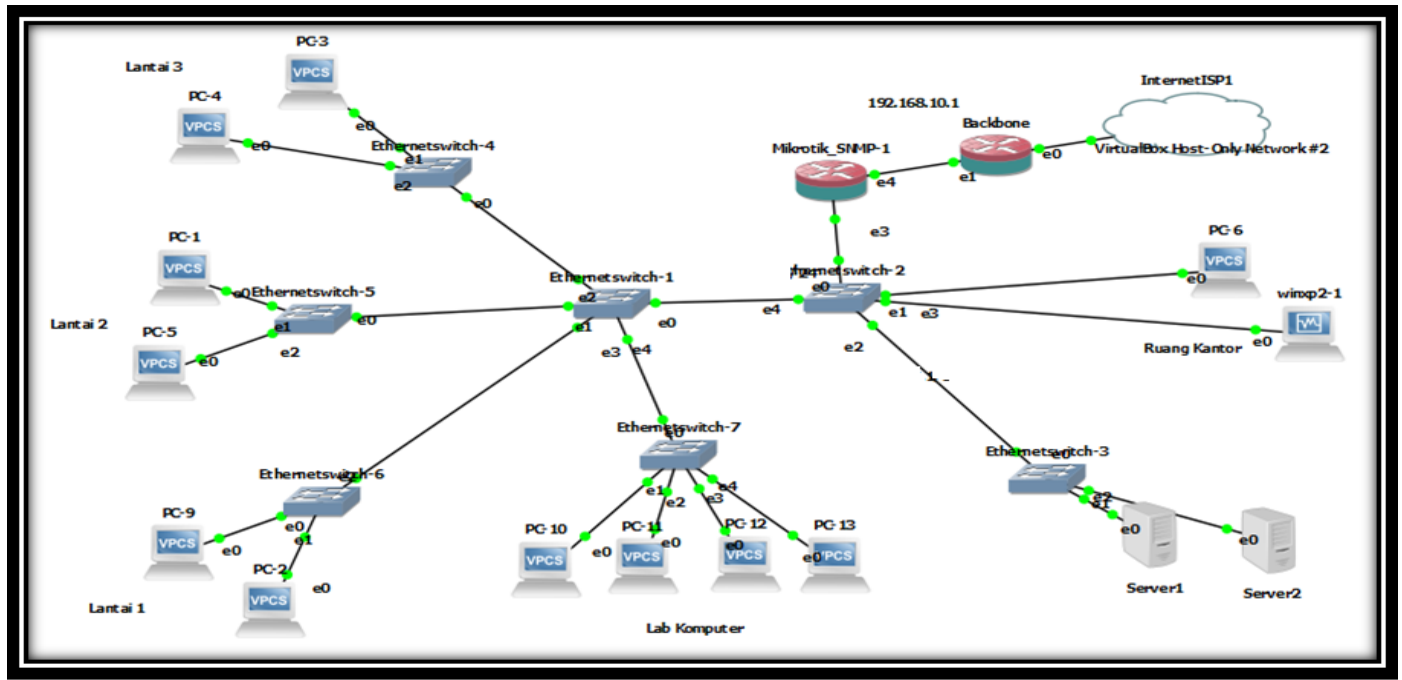

Gambar 6. Desain Topologi Jaringan

Konfigurasi awal pada mikrotik yakni untuk login pada mikrotik dengan username admin sedangkan password dikosongkan.

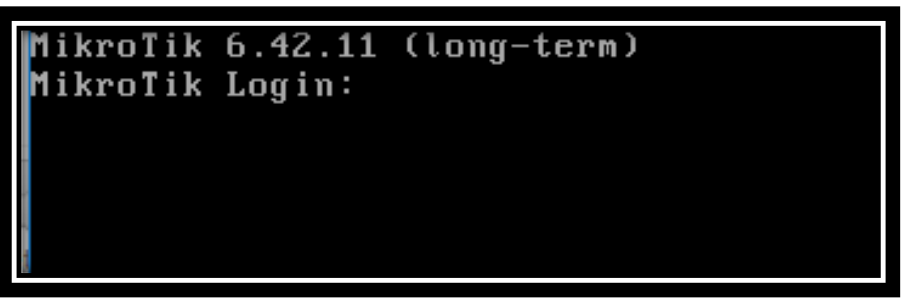

Gambar 7. Tampilan Login pada Router Mikrotik

Guna menampilkan interface yang tersedia pada mikrotik, perintah yang digunakan yaitu int pr (Interface Print), seperti ditunjukkan pada gambar 8.

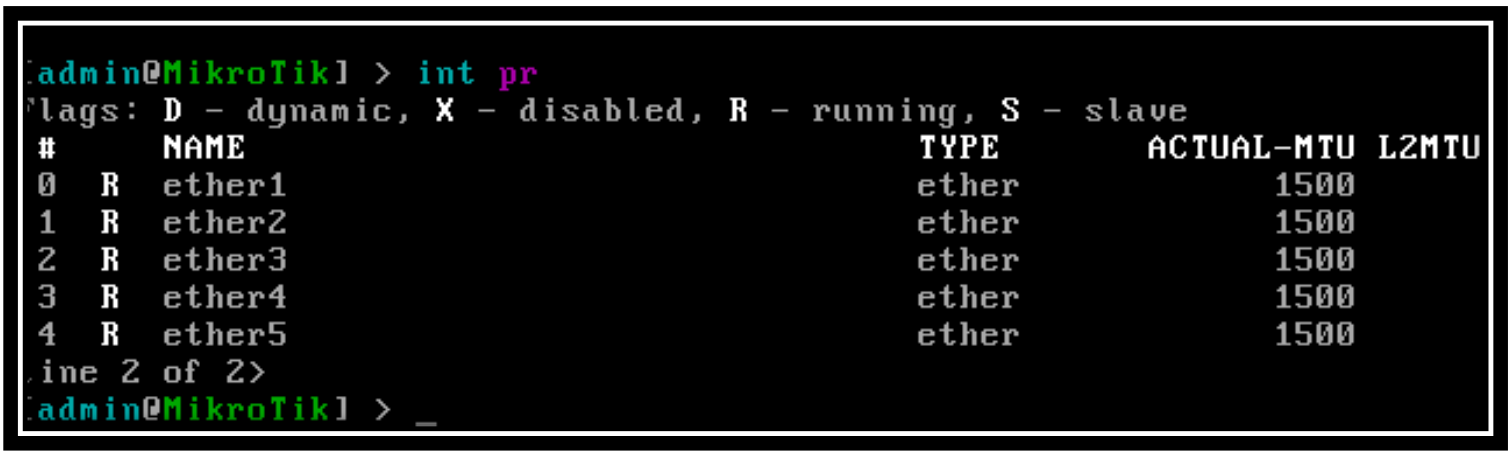

Gambar 8. Tampilan Interface atau ethernet Mikrotik

Setting IP Address pada interface/Ethernet tujuannya untuk memberikan IP Address yang akan digunakan untuk menghubungkan perangkat-perangkat jaringan. 
admineMikroTik] > ip address add address=192.168.10.2/24 interface=ether1 adminEMikroTik] > ip address add address=20.20.20.1/24 interface=ether5

admineMikroTik] >

Gambar 9. Memberikan IP Address pada Interface Mikrotik

Guna menampilkan IP Address digunakan perintah ip address print, seperti ditunjukkan pada gambar 10.

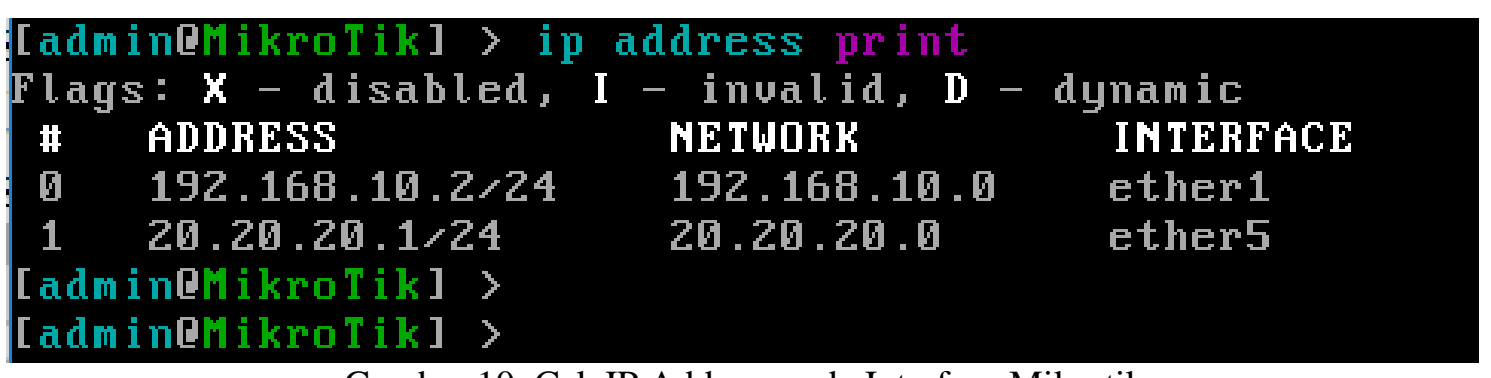

Gambar 10. Cek IP Address pada Interface Mikrotik

Aktifkan Protokol SNMP pada Router Mikrotik, agar semua perangkat dapat dimonitor melalui aplikasi The Dude. Setting awal yaitu pada SNMP Community dengan nama: stikomcki, read-access=yes, dan write-access=yes.

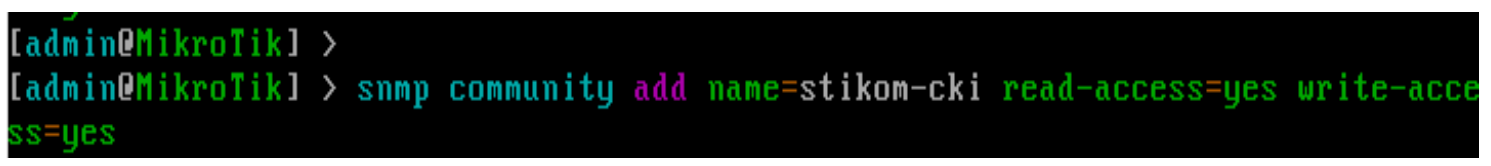

Gambar 11. Setting SNMP Community

Selanjutnya, pada set contact=alamat email yang digunakan, enabled=yes, location=tempat yang akan dimonitor, trap-community=stikom-cki, trap-version=3.

\section{[adminEMikroTik] > snmp set contact=zaeniCgmail.com enabled=yes location=R-Pusat trap-community=stikom-cki trap-version=3}

\section{Gambar 12. Setting SNMP}

Tiap PC atau laptop yang telah diberikan IP Address mengikuti pada tabel selanjutnya diuji dengan tes ping ke router dan ke masing-masing PC. Hasil pengujian ke perangkat jaringan ditunjukkan pada gambar 13.
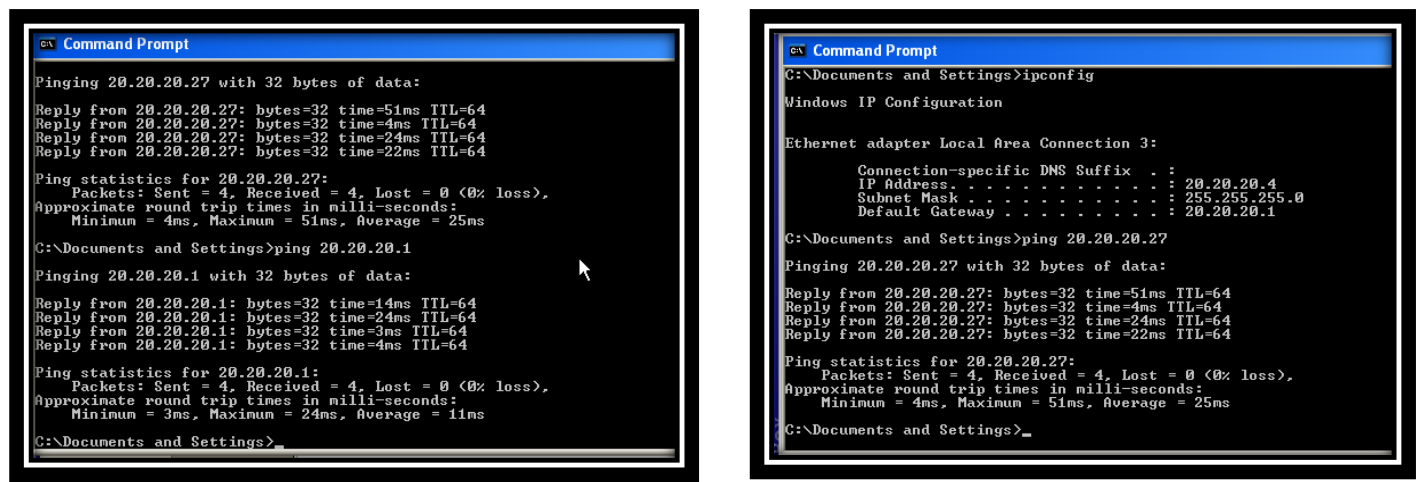

Gambar 13. Pengujian dengan ping 
Jalankan aplikasi The Dude, pada bagian server pilih IP Address pada router dan tekan tombol Connect.
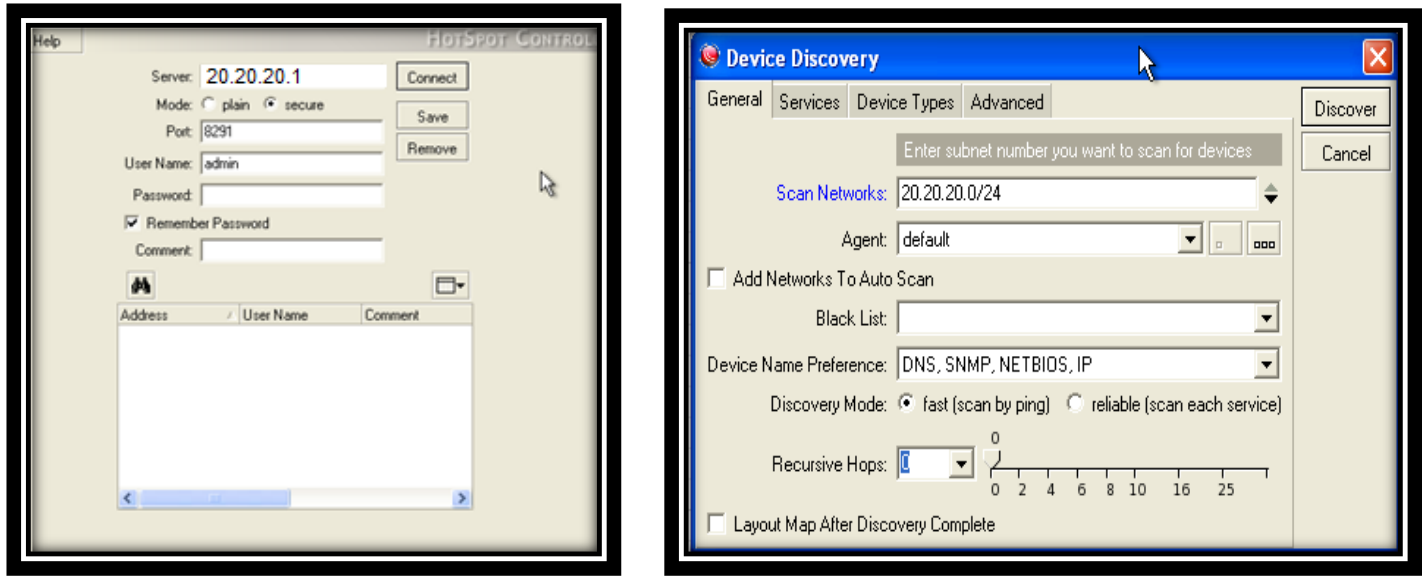

Gambar 14. Koneksi The Dude dengan SNMP Mikrotik

Pada aplikasi The Dude pilih Discovery dan lakukan scan networks sehingga perangkat yang terhubung akan tampil pada aplikasi The Dude. Jika ingin melihat secara detail terhadap perangkat jaringan tertentu, maka mouse dapat diarahkan ke perangkat tersebut seperti ditunjukkan pada gambar 15.
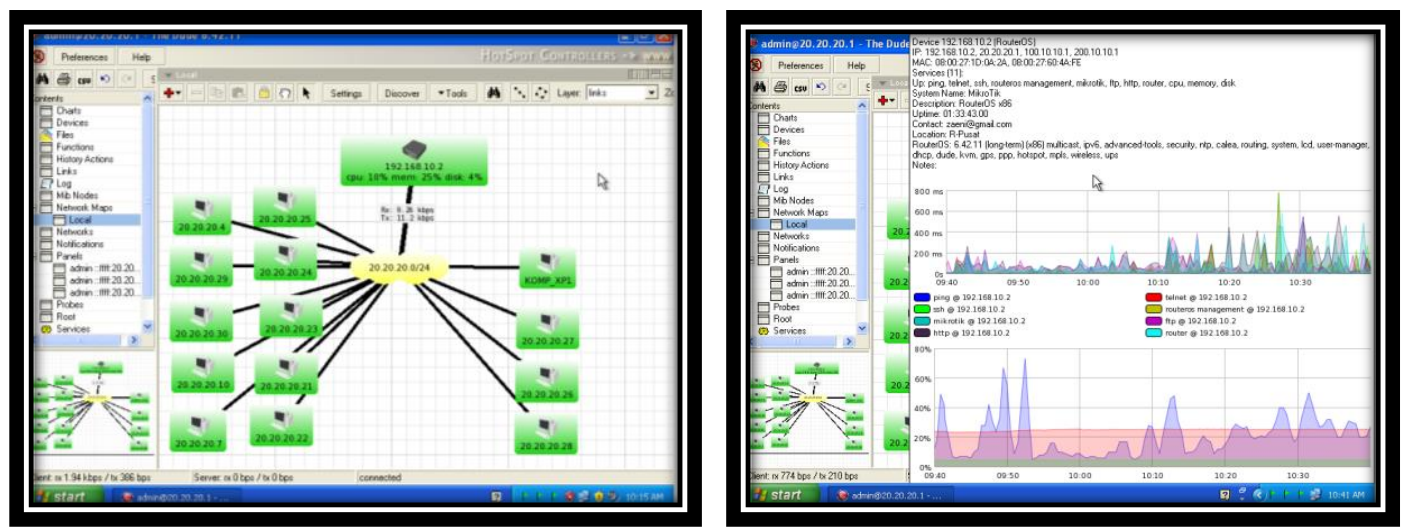

Gambar 15. Tampilan Koneksi Jaringan

\section{Pengujian pada PC dengan Koneksi Jaringan Terputus}
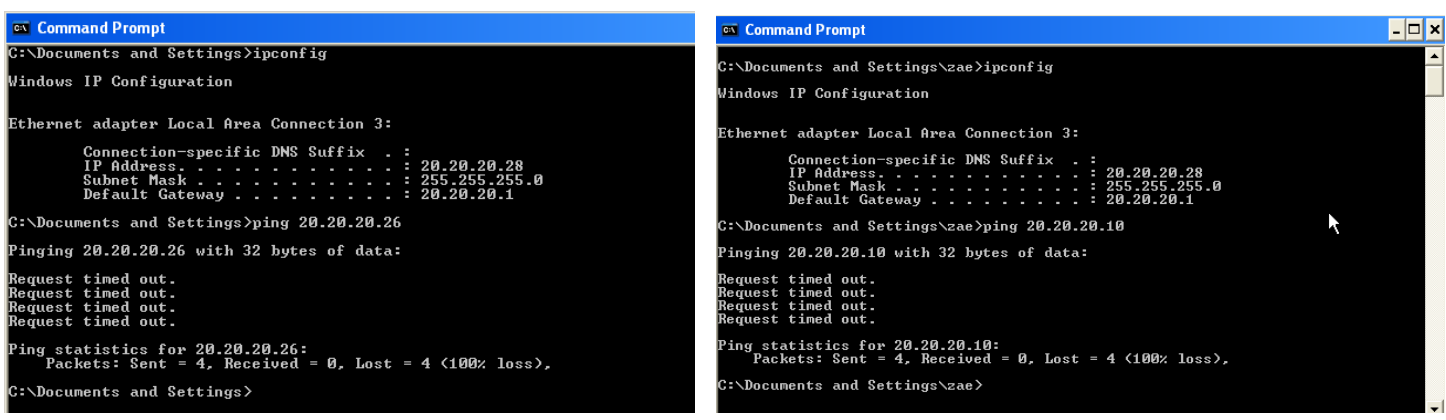

Gambar 16. Pengujian dengan ping

Jika ada PC atau perangkat jaringan yang terputus dengan jaringan, maka pada tampilan The Dude perangkat tersebut akan berubah menjadi merah. 


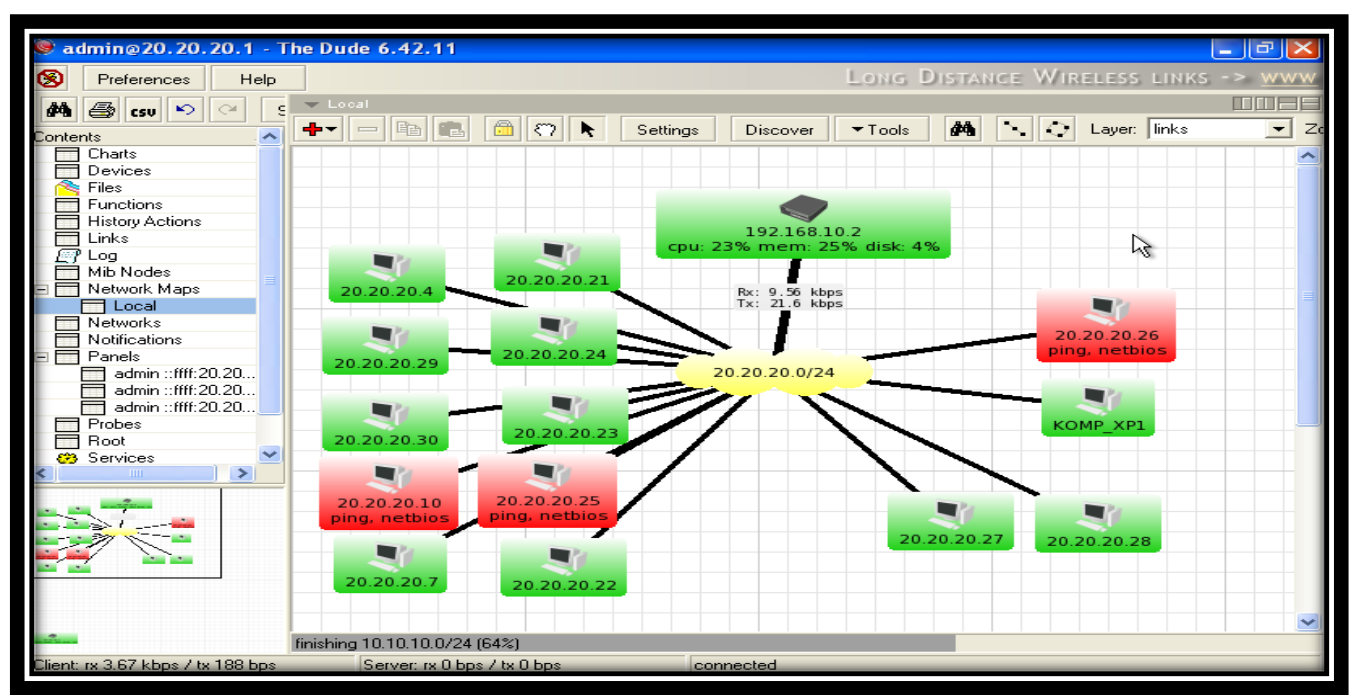

Gambar 17. Pengujian dengan The Dude

\section{PENUTUP}

\section{Simpulan}

Berdasarkan implementasi dan pengujian sistem yang telah dilakukan, dapat disimpulkan bahwa dengan menggunakan Sistem Monitoring Jaringan dengan Protokol SNMP pada router Mikrotik dan aplikasi The Dude di STIKOM Cipta Karya Informatika, maka dapat membantu pengelolaan jaringan di STIKOM Cipta Karya Informatika.

\section{Saran}

Perlu ditambahkan bentuk notifikasi koneksi terputus melalui email atau (Short Message Service) SMS sehingga memudahkan bagi administrator jaringan pada saat diluar area.

\section{DAFTAR PUSTAKA}

Adi, W. (2015). Implementasi Monitoring Jaringan Komputer Menggunakan Dude. Teknologi Informasi, 11, 1-10.

Hui-Ping, H., Shi-De, X., \& Xiang-Yin, M. (2015). Applying SNMP Technology to Manage the Sensors in Internet of Things. The Open Cybernetics \& Systemics Journal, 9, 1019-1024.

Pratama, M. R., Elektro, F. T., Telkom, U., Elektro, F. T., Telkom, U., \& Data, T. B. (2017). IMPLEMENTASI DAN ANALISIS SISTEM MONITORING MENGGUNAKAN SIMPLE NETWORK MANAGEMENT PROTOCOL ( SNMP ) PADA GEDUNG A , N , $O$ DI JARINGAN TELKOM IMPLEMENTATION AND ANALYSIS OF MONITORING SYSTEM USING SIMPLE NETWORK MANAGEMENT PROTOCOL ( SNMP ) ON A , N , O BU, 4(2), 2092-2099.

Setiawan, J., \& Sabiq, A. (2018). Pemantauan Jaringan Menggunakan The Dude pada CV Teknika Bangun Wacana Berbasis Mikrotik dan Web. JTT (Jurnal Teknologi Terpadu), 6(1), 67. https://doi.org/10.32487/jtt.v6i1.441

Sivakumar S.R., M. . (2012). Network Monitoring Using SNMP Protocol. Network Monitoring Using SNMP Protocol, 3(1), 64-66. Retrieved from http://www.ijcns.com/pdf/ijpcsc14.pdf 